\title{
Conflictos de intereses: Una propuesta académica
}

\author{
Conflicts of interest: \\ An academic proposal
}

$S_{\text {rin }}^{\text {r. }}$ Editor: El tema de los conflictos de intereses n la práctica médica, recibe cada vez más la atención de instituciones médicas y los médicos. El Colegio Médico de Chile (AG) ha incorporado en la nueva versión de su Código de Etica un capítulo específico sobre el tema ${ }^{1}$. La Asociación de Sociedades Científicas-Médicas de Chile ha difundido recomendaciones para el control de estos conflictos ${ }^{2}$ y diversos médicos se han pronunciado sobre los mismos ${ }^{3}$. Sin embargo, los conflictos de intereses siguen presentes y los que guardan relación con la industria farmacéutica han alcanzado notoriedad pública 4 .

Algunos países han llegado a la regulación legal de la interrelación médico-industria. Pienso que previamente es conveniente agotar todas las posibilidades de autorregulación de esta relación. Al respecto, resulta de interés una publicación reciente de un grupo de médicos provenientes de diferentes escuelas médicas norteamericanas, que proponen una política frente a las prácticas médicas que crean conflictos de intereses ${ }^{5}$. Este grupo, después de reconocer la amenaza que el asunto conlleva para el ejercicio del profesionalismo médico y la confianza de los pacientes en sus médicos, estiman que el remedio y la prevención deben venir a través de una estricta regulación, de los centros médicos universitarios y las escuelas médicas, porque ellos ejercen un liderazgo organizado y eficiente, y tienen la responsabilidad principal en la formación y entrenamiento de los futuros médicos y especialistas.

\section{REFERENCIAS}

1. http://www.colegiomedico.cl/area gremial.asp? ids=353 (consultado el 17 de marzo, 2006).

2. Documento. Rev Méd Chile 2005; 133: 607-8.

3. JADRESIC E, Correa E. El conflicto de intereses en medicina: una preocupación de la Sociedad de Neurología, Psiquiatría y Neurocirugía. Rev Chil Neuro-Psiquiat 2004; 42: 22-8.
Entre sus proposiciones, este grupo señala que debe ser prohibido todo tipo de regalos provenientes de la industria a los médicos. Del mismo modo, el pago de comidas, la compensación económica por viajes o tiempo en congresos. También señalan que debería ser prohibida la entrega directa al médico de muestras médicas. En cuanto al apoyo de la educación médica continua y de la investigación, por parte de la industria, y que ha sido motivo de preocupación en nuestro medio $^{6}$, este grupo -aun reconociendo la potencial reducción de la contribución de la industriaaboga por una política que no permita el financiamiento directo de estos eventos hacia médicos determinados. Sus propuestas apuntan en general a una institucionalización de la recepción de las contribuciones y evitar la relación directa entre un médico determinado y la industria.

Esta política, de este grupo académico universitario, si bien puede parecer extrema, tiene de interés que dirige la regulación de los conflictos de intereses a las escuelas médicas y centros universitarios, y puede convertirse en una invitación a que dichas instituciones se incorporen a la reflexión nacional sobre el tema y puedan proponer las mejores alternativas de solución para tan importante problema.

\section{Dr. Alexis Lama T.}

Escuela de Medicina, Universidad Andrés Bello.

4. Los conflictos de intereses en la guerra de la insulina. La Nación, Santiago 19 febrero, 2006.

5. Brennan TA, Rothman FJ, Biank L, Blumenthal D, Chimonas SC, Cohen JJ. Health Industry Practices that create conflicts of interest. A policy proposal for Academic Medical Centers. JAMA 2006; 295: 429-33.

6. Reyes H. Comentarios de un lector. Los médicos y la hospitalidad de la industria. Rev Méd Chile 2004; 132: 265-8. 